University of Nebraska - Lincoln

DigitalCommons@University of Nebraska - Lincoln

2004

NEMATODE MOLECULAR DIAGNOSTICS: From Bands to

Barcodes

Tom Powers

University of Nebraska - Lincoln, tpowers1@unl.edu

Follow this and additional works at: https://digitalcommons.unl.edu/plantpathpapers

Part of the Other Plant Sciences Commons, Plant Biology Commons, and the Plant Pathology Commons

Powers, Tom, "NEMATODE MOLECULAR DIAGNOSTICS: From Bands to Barcodes" (2004). Papers in Plant Pathology. 640.

https://digitalcommons.unl.edu/plantpathpapers/640

This Article is brought to you for free and open access by the Plant Pathology Department at DigitalCommons@University of Nebraska - Lincoln. It has been accepted for inclusion in Papers in Plant Pathology by an authorized administrator of DigitalCommons@University of Nebraska - Lincoln. 


\title{
Nematode Molecular Diagnostics: From Bands to Barcodes
}

\author{
Tom Powers \\ Department of Plant Pathology, University of Nebraska Lincoln, Lincoln, \\ Nebraska 68583-0722; email: TPowers@unl.edu
}

Key Words DNA barcode, plant parasitic nematodes, identification, 18S ribosomal DNA, internally transcribed spacer

- Abstract Nematodes are considered among the most difficult animals to identify. DNA-based diagnostic methods have already gained acceptance in applications ranging from quarantine determinations to assessments of biodiversity. Researchers are currently in an information-gathering mode, with intensive efforts applied to accumulating nucleotide sequence of $18 \mathrm{~S}$ and $28 \mathrm{~S}$ ribosomal genes, internally transcribed spacer regions, and mitochondrial genes. Important linkages with collateral data such as digitized images, video clips and specimen voucher web pages are being established on GenBank and NemATOL, the nematode-specific Tree of Life database. The growing DNA taxonomy of nematodes has lead to their use in testing specific short sequences of DNA as a "barcode" for the identification of all nematode species.

\section{INTRODUCTION}

Molecular diagnostics of nematodes will soon be commonplace. The field has moved beyond initial technical development to the present stage of data accumulation. PCR has enabled the rapid collection of vast amounts of genetic data, information that may provide the raw material for reliable nematode identification. Any investigator given a set of specific primers, a thermal cycler, a few stock reagents, and a means to evaluate the amplified PCR product, can quickly generate enough data to require intensive bioinformatics analysis. One glance at a current nematology journal will confirm the abundance of papers comparing nematode nucleotide sequences or restriction enzyme patterns. In nematode identification the central question is no longer one of the relative importance of molecules versus morphology, but "what is the message in the molecule, and how can we best interpret that message?" A well-formulated approach to that question will create a solid framework for future studies of nematode biodiversity. Haste in the process of nematode characterization could lead to a molecular Tower of Babel.

Nematode diagnostics has traditionally relied on careful measurement and comparison of morphological structures. This process has revealed significant variation 
in those structures. Often discrimination between species is based on average measurements from a population of individuals, a tricky business if populations consist of mixtures of closely related species. Nonetheless, over a century of descriptive biology has led to the recognition of approximately 25,000 nematode species and the widely held estimate that 10-40 times as many species remain to be described. Within the next decade each of the nominal species could conceivably be characterized by molecular methods. But the speed and ease of data acquisition may belie the real difficulty of accurate nematode identification.

The first step in the development of diagnostic protocols usually involves the selection of an "exemplar" or representative specimen of the taxon. The identification of the exemplar is critical. Ironically, this crucial first step is often the least critically examined step in diagnostic studies (53). The construction of the rapidly growing molecular database must include a means to evaluate the quality of the data. Without adequate documentation or designation of voucher material we are left wondering what, exactly, does a DNA sequence represent. Ideally, each DNA sequence in GenBank or each published PCR-RFLP gel pattern should be accompanied by extensive information about that specimen. This information could include photographs, measurements, collection site data, and status of voucher material. The voucher material may consist of DNA, digitized images, video or a portion of the original specimen (20a). This has been the standard for traditional, morphological-based diagnostic research, and there should be no relaxing of those standards for molecular studies.

\section{ADVANTAGES OF MOLECULAR DIAGNOSTICS}

\section{Morphologically Similar but Genetically Divergent}

Nematodes are remarkably constrained morphologically. Caenorhabditis elegans and C. briggsae are two free-living nematodes whose discrimination would present a challenge to most trained nematode taxonomists. Yet in spite of their morphological similarity, a recent comparison of 338 orthologous genes (homologous genes derived from the same gene in the last common ancestor) resulted in an estimated date of divergence between the two species of 80-110 Mya (52a). This splitting event occurred 5-45 million years before the splitting of the mouse and human lineage (64). Whereas most of us feel comfortable in making the manmouse discrimination, this example sends a powerful message to those faced with identification of nematode species. Clearly, cryptic species must abound in the phylum Nematoda, and molecular techniques may be the only practical approach to recognize them.

\section{Speed and Simplicity}

Modern identification methods must provide accuracy, speed, reliability, affordability, and if possible, enable characterization of specimens new to science. 
Molecular approaches are becoming more widely applied to fulfill these new demands, in part because of the relative simplicity of their application in the laboratory. Most nematodes are approximately $1 \mathrm{~mm}$ in size and comprised of 1000 to 2000 cells. Conveniently, this size is suitable for a PCR reaction with a minimum effort required for sample preparation. There are no hard structural parts to a nematode that must be separated or circumvented to get at the DNA. In many cases, the nematode may simply be crushed in a droplet of water and a portion of the solution added directly to a PCR reaction (48). Other preparation methods include a proteinase digestion and DNA purification step $(22,51 \mathrm{a})$. Multiple amplifications (5-10) can routinely be achieved from a single nematode. The solution from a crushed nematode can be stored frozen indefinitely and thereby serve as a DNA voucher for future analysis.

\section{Better Targeting of Problem Nematodes}

With the pending elimination of general biocides, alternative strategies for managing nematodes by necessity must focus on control procedures for a specific nematode species, groups of species, or a subspecific taxa. Future diagnostic methods will require greater specificity across a broad range of nematode taxa.

\section{Application to All Life Stages}

Surveys of nematode communities illustrate the difficulties in species identification. For accurate identification, most keys require critical decisions on adult characteristics. Nematode populations often are comprised of a large percentage of juveniles. In groups such as Dorylaimida successful navigation of keys requires both sexes, yet specimens are found in such low frequency that species determinations must be made on a single sex. Molecular markers can, and in some situations must, be used to identify all life stages. For example, only molecular methods have proved to be reliable in identifying infective juveniles of M. mayaguensis in the soil (12).

\section{Mixed Nematode Populations}

Seldom in an agroecosystem is an individual plant fed upon by a single species of plant-parasitic nematode. Multiple plant-parasitic species are typically recovered from the roots of a single plant, and in some situations, the community composition of plant-feeding nematodes in an agronomic soil reflects the specific sequence of cropping systems and rotation schemes over the course of several years. Monitoring the identity and abundance of all the nematodes in the soil community has been advocated as a key component in the modern vision of integrated pest management (41). Even when a subset of the nematode community is targeted for control, researchers are discovering that nematode diversity is greater than previously expected. For example, it appears that many agronomic soils contain mixtures of root-knot species (Meloidogyne), each species with its unique host ranges and life-history characteristics. 


\section{Emerging Parasites}

Improved molecular diagnostics will help identify and address unforeseen threats to agricultural crops. A recent survey of nurseries and agronomic soils in southern Florida found nematode communities comprised of at least three nominal species of root-knot nematodes (12). One of the species recovered from Florida fields, $M$. mayaguensis, has the ability to reproduce on nematode-resistant rootstock, and had gone undetected due to its morphological similarity to $M$. incognita (and the fact that the common management practice, application of general biocides, did not require discrimination among nematode species).

\section{Import and Export}

The discrimination of nematodes at the species level becomes essential when agricultural commodities move across international borders. In 2000, the Nematology Laboratory in the California Department of Food and Agriculture made an average of 15 quarantine-related identifications each day (37a). Quarantine regulations target dozens of species depending on the commodity. Many of these regulated species are members of extremely large genera containing numerous described species. In the case of regulated species such as the potato cyst nematodes Globodera rostochiensis and $G$. pallida, and the Columbia root-knot nematode M. chitwoodi, the presence of a single individual can lead to the rejection of an entire shipment of potatoes intended for export. That one individual may exist among numerous nontarget, but closely related, species. In order to address quarantine and management problems, speed, sensitivity, accuracy, specificity, and broad applicability will be required features of any prospective nematode identification protocol.

This review presents the concept of a genetic "barcode" for nematode diagnostics and focuses on molecular studies that might influence the development and implementation of future diagnostic protocols. It concentrates on the genetic regions that have been used in nematode molecular diagnostics, first with a short overview of the genetic markers, and then evaluates their application with select nematode taxa. Other reviews of nematode molecular diagnostics have taken a more comprehensive or chronological approach $(36,67)$. Reviews of animal parasitic nematodes are available elsewhere (39).

\section{DNA BARCODE AS A DIAGNOSTIC TOOL}

The concept of using a single piece of DNA to identify all life forms on earth was discussed at two conferences held at Cold Spring Harbor Laboratory in 2003. The piece of DNA would be called a "DNA barcode" or a "barcode of life" (3a, $33,45,54,54 \mathrm{a})$. The DNA barcode is analogous to the Universal Product Codes commonly seen on retail products. Rather than a numeric code, the nucleotide sequence from a common gene would serve as a unique identifier for every species. 
Theoretically, a single 600-nucleotide fragment of protein-coding DNA could easily contain enough variation to identify the estimated 10 million species inhabiting the planet. Even a conserved gene fragment with evolutionary constraints on protein sequence variation could provide sufficient information for a universal barcode. In the example above, if the first two positions in the 200 codons of the 600-nucleotide fragment were invariant, and the third positions were constrained to two possible nucleotides by nucleotide bias, there would still be $2^{200}$ or $10^{60}$ possible sequences derived from this small fragment of DNA (54). Validation of the barcode concept, however, rests on more than theoretical information content of DNA.

Based on experience of forensic sequencing at the World Trade Center, J. Craig Venter, from the Center for the Advancement of Genomics, estimated it would currently take 2 weeks to complete amplification and diagnostic single gene sequencing of 100,000 insect legs at a cost of $\$ 1$ a sample. He speculated that within 5-10 years sequencing facilities will have the capacity to sequence entire mammalian genomes in seconds. Because of these technological advances and the information content of entire genomes, Venter advocates a strategy of whole genome sequencing as opposed to the development of a single gene barcode approach. Herbert et al. $(25,26)$ demonstrated that a barcode based on the mitochondrial gene cytochrome c oxidase subunit 1 (COI) can provide accurate species identification across broad divisions of the animal kingdom. His proof-of-concept studies included a comparison of 13,000 congeneric species pairs representing 11 phyla. The estimated mean divergence of these species pairs was $11.3 \%$, with $98 \%$ of the pairs exhibiting divergence at greater than $2 \%$. The diversity of COI may be sufficient for barcoding animals, and used solely for the purpose of identification, the single gene approach appears promising. Given the rapid rate of species extinction and the accelerated threat of emerging diseases, many scientists believe the justification for barcoding is compelling, and is a process that cannot be postponed without consequence.

While argument exists about what a "barcode of life" might look like, research projects are underway to test the barcode concept. Regardless of the strategy ultimately adopted, it is clear that the process will affect the development of molecular diagnostics for nematodes. Nematodes are already among the first organisms used to test the barcode concept $(6,23)$. Nematodes can rapidly be extracted, sorted, and counted from soil or other substrates. When phylogenetic breadth and diversity are important, nematodes extracted from a single $100 \mathrm{cc}$ soil sample could provide representative species from many of the major taxonomic groups in the phylum, representing over 800 million years of phylogenetic divergence (5). That same soil sample could include 50-100 different nematode species and thousands of individuals in all life stages $(4,11)$. The question of phylogenetic diversity and applicability is important in barcode development. A barcode that is readily incorporated into a phylogenetic framework takes advantage of the predictive power of evolutionary history.

Interpreting the signal from a $18 \mathrm{~S}$ ribosomal DNA barcode, Floyd et al. (23) were able to place unknown nematodes sampled from a Scottish upland grassland 
onto a phylogenetic tree. Currently, there is insufficient information in the nematode databases for extensive species identification based on the $18 \mathrm{~S}$ barcode, but one glance at the tree permits an educated guess regarding the taxonomic affinities of their unknown nematode samples. The expanding $18 \mathrm{~S}$ nematode tree $(7$, 20) will become a valuable resource through the collective efforts of contributors to GenBank and NemATOL, the NSF-funded nematode branch of the Tree of Life Project (http://nematol.unh.edu/). NemATOL will synergistically benefit diagnostic efforts by serving as a repository for sequence information and "collateral" biological data. Like GenBank with its LinkOut connections, NemATOL is an open database containing an archived collection of nematode video images, morphological information, DNA sequences, alignments, and other reference material.

\section{GENETIC REGIONS COMMONLY USED FOR DIAGNOSTICS}

Two genomic regions have been routinely characterized among nematode taxa: the ribosomal RNA array and the mitochondrial genome. The ribosomal RNA genes and their intervening sequences are the best-characterized genes or gene regions in Nematoda. The RNA genes themselves are highly conserved, but diagnostically useful variation is found both in discrete regions of the genes and in the length and sequence of the spacer regions. The ribosomal genes evolve slowly compared to their spacer regions, yet surprisingly, they retain considerable diagnostic value at the species level in Nematoda. The spacer regions have been widely applied as diagnostic markers at the species level, and their suitability to identify species is best evaluated on a case-by-case basis (see below).

Typically, the rRNA array consists of three ribosomal genes (rRNA), 18S, 5.8S, and $28 \mathrm{~S}(26 \mathrm{~S})$. These genes, together with their spacer regions, are aligned in repeating units; a single unit in $C$. briggsae measures 7429-7431 bases (52a). C. briggsae has 55 tandemly aligned units, whereas $C$. elegans is believed to have 100-150 copies of the repeating unit located on chromosome I. Little is known of the chromosomal location of the rDNA array in other nematodes, although variation in the basic composition of the ribosomal array exists in the plant-parasitic nematode genera Meloidogyne (62). In that genus one copy of the 5S ribosomal gene is located in the intergenic spacer region between the $28 \mathrm{~S}$ and $18 \mathrm{~S}$ genes, an arrangement that has been exploited in several PCR-based diagnostic protocols (8). In $C$. elegans the $5 \mathrm{~S}$ genes are distantly located in a tandem array of approximately 100 copies on chromosome V.

The mitochondrial genome is a logical choice for species-specific diagnostic markers $(10,31)$. The entire circular genome is present in high copy number and consists of rapidly evolving genes and conserved regions that allow broad phylogenetic application. Its uniparental inheritance, conserved structure, gene composition, and gene order, permit systematic and ecological genetic studies that span the animal kingdom. Interestingly, it is the unconventional structural 
elements of the nematode mitochondrial genome that have provided promising diagnostic opportunities. A similar gene order and lack of repetitive DNA sequences characterize most animal mitochondrial genomes (13). Nematodes, particularly those in the class Enoplea (Adenophorea), are characterized by a surprising variety in gene order (37). Both major nematode classes, Enoplea and Chromadorea (Secernentea), have mitochondrial genomes with unusual gene structure and repeated sequences. The repeated regions in Meloidogyne have been converted to species-specific markers and used to examine nematode population structure $(9$, 66). Taxon-specific applications of the mitochondrial genome are considered in the following sections.

\section{Meloidogyne}

Siddiqi (50) lists 80 species of Meloidogyne. It is probably the most economically important group of nematodes, and the need to identify the infective juvenile stages places them among the most difficult plant-parasitic nematodes to identify. The genus includes highly damaging, cosmopolitan species as well as extremely localized species of unknown economic significance. Meloidogyne species are generally considered major problems of tropical crops, although several species are well adapted to colder climates. A relatively small subset of the described species has been examined by molecular methods.

The genetic diversity within Meloidogyne becomes apparent when species outside the mitotic parthenogenetic "trio" of similar species, $M$. arenaria, $M$. incognita, and M. javanica, are compared. De Ley et al. (19) included 14 Meloidogyne species in a phylogenetic comparison using nearly complete $18 \mathrm{~S}$ rDNA sequence (1577-1597 bp). Within the genus there was up to $10 \%$ sequence divergence in pairwise comparisons among species, corresponding to considerable diversity for a relatively conserved gene. Positive from a diagnostic perspective are 1-89 autapomorphies, characters unique to a taxon, observed among this collection of species. These unique character states at polymorphic sites in the $18 \mathrm{~S}$ gene can be exploited in the design of species-specific primer binding sites. Although the investigators only used a single isolate to represent each species in this study, validation through the comparison of additional isolates would support the $18 \mathrm{~S}$ sequence as a barcode of sufficient variation to identify Meloidogyne species.

Chen et al. (16) focused on the D3 expansion region in the 28S ribosomal gene from the trio of mitotic parthenogenetic species plus seven mitotic parthenogenetic isolates of $M$. hapla. Sequence analysis of the 350-bp region showed a fundamental division between the isolates of $M$. arenaria, $M$. incognita, $M$. javanica, and $M$. hapla. Species boundaries among the trio were obscured by the possession of five different D3 haplotypes among the three species, with one haplotype found in isolates of all three species. Four D3 haplotypes were found among isolates of $M$. incognita. A single D3 haplotype was recovered from $M$. javanica. This study sheds light on the origin of the mitotic parthenogenetic species and possible hybridogenetic speciation events, but suggests caution in applying the D3 region alone as a species diagnostic. 
The internal transcribed spacer region (ITS) and the intergenic spacer region (IGS) display considerably more variation among Meloidogyne species than does the D3 region. Petersen \& Vrain (47) demonstrated that PCR primers designed to amplify IGS could discriminate between the facultatively parthenogenetic species $M$. chitwoodi and the morphologically indistinguishable parasite of potato, M. fallax. A 100-bp size difference in the amplified IGS product separated the two species, and M. hapla IGS was approximately $2 \mathrm{~kb}$ smaller than both species. Four isolates of M. hapla, three of $M$. chitwoodi, and three of M. fallax were used in this study. Zijlstra et al. (71) examined 25 isolates of M. hapla, $M$. chitwoodi, and M. fallax and determined that restriction digestion of the amplified ITS product could differentiate among the three species. Using these three species, mixed species populations were tested by digesting the amplified ITS product from DNA extracted from the species mixtures. Good correspondence was observed between the ratio of digestion fragments derived from the different species and the known species frequency in the mixtures (71). ITS may perform well as a diagnostic for Meloidogyne species that reproduce sexually or by facultative parthenogenesis, but it is clear from the research of Hugall et al. (30) that the use of the ITS region for identification of the mitotically parthenogenetic species could easily lead to misdiagnosis. Earlier, Hugall et al. $(28,29)$ demonstrated that mitochondrial haplotypes completely corresponded to groupings based on esterase isozyme phenotypes. This strict correlation was recently demonstrated in an examination of 46 Meloidogyne populations from 14 provinces in China (69). According to the designations of Hugall et al. (29), mitochondrial haplotype B corresponded to the I1 esterase pattern of $M$. incognita, haplotype D to the $\mathrm{J} 3$ esterase pattern of $M$. javanica, and $M$. arenaria had two haplotypes, A, which corresponded the A1 esterase pattern, and C, which was associated with esterase pattern A2 and A3. The ITS region, however, displays remarkable patterns of variation, undoubtedly the echo of a hybrid ancestry. There are two divergent and distinct clusters of ITS variants found within these three species. The divergence between ITS clusters ranges from $14 \%$ to $18 \%$. Variants from both clusters can be recovered from isolates containing each of the mitochondrial haplotypes. Hugall et al. (30) examined one ITS cluster in depth by sequencing multiple clones from isolates representing the four mitochondrial haplotypes. In a total of 151 clones they recovered 89 different ITS variants with an average total nucleotide diversity of 7.2\%. Typically, an individual of these three species possesses 9-13 ITS variants. As in the D3 region, patterns of ITS variation may help sort out potential parents in a hybrid speciation event, but they will be misleading as a species diagnostic.

The unusual location of the 5S ribosomal gene in the IGS region of Meloidogyne inspired Blok et al. (8) to design primers in the $5 \mathrm{~S}$ gene and the $5^{\prime}$ portion of the $18 \mathrm{~S}$ gene to assess polymorphism. They discovered that the amplified product of the tropical root-knot nematode $M$. mayaguensis differed sufficiently from other species found in the tropics to sort species by product size on agarose gels. The mitotically parthenogenetic trio was nearly identical in sequence, with $M$. incognita exhibiting a single substitution and deletion for the 715-bp region when compared 
with $M$. arenaria and $M$. javanica. The latter two species displayed intraspecific variation among cloned IGS products.

The mitochondrial genome shows extensive variation in Meloidogyne. Powers \& Harris (48) investigated a region of the mitochondrial genome between the $5^{\prime}$ portion of the cytochrome oxidase subunit II (COII) gene and the large (16S) ribosomal gene. Between these two genes lies the tRNA histidine and an intervening region characterized by insertions or deletions resulting in size polymorphism when amplified by PCR primers in the flanking genes. At least four major size classes have been identified $(9,44,48,51)$. The smallest class, in which only a few to 60 nucleotides comprise the intervening sequence, is found in sexually reproducing Meloidogyne species, most facultative parthenogenetic species, and mitotic parthenogenetic M. hapla. M. mayaguensis has two copies of the tRNA histidine gene, creating an amplification product approximately 160 bp larger than M. hapla (9). M. arenaria haplotype A (esterase AI) has an intervening sequence 370 bp larger than $M$. mayaguensis, but approximately 600 bp smaller than mitochondrial haplotypes $\mathrm{B}, \mathrm{C}$, and $\mathrm{D}$, which correspond to the mitotically parthenogenetic species $M$. incognita, M. arenaria, and M. javanica. Stanton et al. (51) outlined a PCR-RFLP diagnostic protocol based on restriction site polymorphism that could distinguish six closely related haplotypes found in Meloidogyne species. Okimoto et al. (42) characterized a unique region of noncoding tandem repeats in the Meloidogyne mitochondrial genome and suggested that it might serve to identify species and host races. Due to the distribution of multiple variants within individuals, the series of 63-bp repeats has been more useful in population studies, where it has been used to partition variation at different hierarchical levels of the mitotically parthenogenetic species $(18,38,66)$. This region recently was recognized for its diagnostic potential by its ability to discriminate $M$. mayaguensis based on the consistent presence of a single 322-bp size product when amplified with primers binding to the flanking tRNA serine and noncoding region (9). Using the same primer set, the mitotically parthenogenetic species produce multiple amplification products of varying intensity, or no product as in the case of M. hapla.

Most of the diagnostic protocols mentioned above, based on mitochondrial DNA, will be limited in application as barcode technology since they exploit unique characteristics of the Meloidogyne mitochondrial genome. Differences in mitochondrial gene order limit approaches that use primer sets that cross gene boundaries, and the amplification of dynamically changing noncoding repeated sequences makes phylogenetic analysis extremely difficult. There has been no systematic survey of COI sequences among plant-parasitic nematodes, although the proof-of-concept papers of Herbert et al. $(25,26)$ and a recent analysis of the tylenchid insect associate Howardula suggest COI will provide good species resolution (46).

Anonymous loci in Meloidogyne have been evaluated through RAPD PCR and AFLP approaches $(8,18,21,24,68)$. Notable among these studies is the conversion of species-specific amplified products to sequence-tagged sites for the identification of M. chitwoodi and M. hapla (68). Their multiplex diagnostic assay was tested 
with 7 North American isolates of M. hapla and 14 isolates of M. chitwoodi from the U.S. Pacific Northwest. PCR produced uniquely sized amplification products in reactions using single juvenile nematodes. Additional testing with other closely related species will further validate this assay.

\section{HETERODERA AND GLOBODERA}

Heterodera and Globodera are generally considered pests of temperate regions, although approximately one third of the 65 described species of Heterodera are known from the tropics (50). The potato cyst nematodes, Globodera rostochiensis and $G$. pallida, are among the most heavily regulated nematodes in agricultural commerce. The resistant cyst stage contributes to their widespread dispersal.

The cyst nematodes currently may be the best-characterized group of plant parasitic nematodes for application of DNA barcoding. Largely through the systematic survey work of Subbotin and coworkers, there exists an extensive database of heteroderid ITS sequences in GenBank $(2,17,56-59,70)$. Over one third of the described species have a representative ITS sequence deposited in GenBank, and phylogenetic analysis suggests a substantial number of new species may be recovered in molecular surveys (56). Descriptions of new species, however, may require a better understanding of intraspecific variation in Heterodera. Most of the recent studies have incorporated ITS-based PCR-RFLP approaches to species identification or used multiplex primer sets, one set as a positive control for amplification and a second set that includes a species-specific primer. Accordingly, these studies have assessed intraspecific variation by evaluating the presence or absence of key restriction sites in the case of PCR-RFLP or primer binding sites in the multiplex PCR assays. For example, Subbotin et al. (57) tested 53 isolates of $H$. glycines using a multiplex assay that included a $H$. glycines-specific primer that bound to a region in ITS2. The primer-binding site in $H$. glycines differed from closely related $H$. medicaginis only in the final $3^{\prime}$ nucleotide of the primer. Amplification products were only produced in the 53 isolates of $H$. glycines. A similar multiplex assay was conducted with similar results for 37 isolates of $H$. schachtii (2). These studies demonstrate that our delimitation of species boundaries for those cyst nematodes studied to date are supported by specific fixed nucleotides that can be exploited for species identification. Phylogenetic analyses further support the grouping of these species into familiar "species complexes" characterized, in part, by host associations $(57,60)$. Subbotin et al. (56) conducted a remarkably thorough analysis of the $H$. avenae species complex, generating 70 ITS sequences from isolates providing worldwide representation of the group. Not surprisingly, extensive variation was observed among the nine species comprising the species complex, and isolates identified as $H$. avenae included several discretely different genotypes. PCR-RFLP and sequencing studies clearly demonstrate that intraspecific variation is common in the ITS region and likely to uncover new species. This variation has also been evidenced as bands of light intensity observed when restriction digestion products are separated on agarose gels or as variant sequences 
derived from cloned amplified PCR product $(58,60)$. In the heteroderid ITS region $0.5 \%-1.5 \%$ intraspecific sequence variation is not uncommon. How this variation is partitioned within individuals, among individuals, or among populations is not yet well understood.

Globodera rostochiensis and G. pallida can be discriminated by several approaches. Subbotin et al. (58) identified three restriction enzymes that differentially digest the ITS region producing patterns consistent with perceived species boundaries. These boundaries are supported by a phylogenetic analysis of 41 Globodera and related ITS nucleotide sequences, providing an evolutionary framework for species delimitation (58). Four distinct clades were identified for members of the genus parasitizing solanaceous plants, corresponding to G. pallida, G. rostochiensis, G. tabacum, and an unidentified species from South America. The D3 expansion region exhibited no nucleotide differences between the two potato cyst species. Mulholland et al. (40) designed a multiplex PCR assay for both species using species-specific primers located in ITS1. Bulman \& Marshall (14) also designed a multiplex PCR reaction from ITS to distinguish the two potato cyst species. Stratford \& Shields (55) used primers specific for a trans-spliced leader gene and the 5S ribosomal gene to develop a PCR assay based on amplified product size differences in the two species. A remarkable discovery in Globodera is the unique structural organization of the mitochondrial genome of G. pallida. Armstrong et al. (3) determined that unlike typical higher metazoa, which possess a single, circular mitochondrial genome, G. pallida possesses six or more small circular genomes ranging in size from $6.3-9.5 \mathrm{~kb}$.

\section{PRATYLENCHUS AND NACOBBUS}

Pratylenchus species are distributed worldwide. Siddiqi (50) lists 89 species in the genus. They are all identified by exceptionally subtle morphological characteristics, most often observed in the adult stages. Key diagnostic features such as number of lip annules, shape of the tail terminus, relative length of the esophageal gland overlap, length of the post uterine sac, and even lateral line number may be difficult to determine. Variability of these characters compounds the identification problem.

Waeyenberge et al. (65) characterized 18 species of Pratylenchus by PCR-RFLP of the ITS region. A minimum of two enzymes are necessary for discrimination of this collection of species. The conclusions in this study must be considered preliminary since 10 of the species were represented by a single isolate. A remarkable ITS size difference exists within the genus; approximately 350 bp separate the smallest and largest amplified ITS region among the species. Intraspecific ITS variation has been observed in Pratylenchus, particularly within isolates of $P$. coffeae (43, $61,65)$. Difficulties in the identification of $P$. coffeae were addressed by Duncan et al. (20b) and underscore the necessity of maintaining specimen vouchers that can be reexamined if necessary by additional molecular markers. Carta et al. (15) used the D3 region of the $28 \mathrm{~S}$ ribosomal gene in a phylogenetic analysis of 19 
Pratylenchus species. Seventeen of the species had unique D3 sequences, although only one species was represented by more than a single isolate. Carta et al. (15) also highlight some of the problems in selecting representative isolates of certain nominal species. This study, together with an earlier examination by Al-Banna et al. (1) of 10 Pratylenchus species using D3 clearly illustrate difficulties associated with assessing species boundaries and relationships in a poorly characterized genus comprised of amphimictic, parthenogenetic, and polyploid species.

Nacobbus, the false root-knot nematode, is a regulated species in which species determinations shape quarantine decisions. A turbulent taxonomic history and evidence of physiological variation led to the belief that $N$. aberrans, the primary pest species in the genus, is actually a species complex $(32,34,35)$. Recent ITS sequencing from 12 isolates from South America and Mexico tends to confirm the existence of distinct subgroups (49). Missing from these analyses are crucial North American biotypes and representative of the type species, N. dorsalis.

\section{XIPHINEMA}

The dorylaim plant-parasites pose special challenges for molecular diagnostics. They are found in relatively low frequency in samples, multiple species are typically present in fields, and it is important to identify potential virus vectors. Wang et al. (63) designed sets of primers from ITS sequences to identify four species of Xiphinema known to transmit virus. These primer sets worked well in multiplex combinations in amplifications from individual specimens. Hubschen et al. (27) extended the testing of these primers to include dilution series of vector:nonvector Xiphinema DNA at levels of 1:800. The primers were further tested in experiments in which a single vector species was added to a community of nematodes extracted from the soil. Following bulk DNA extraction the vector-specific primers were able to detect the presence of the vector specimen. The recent studies of Hubschen et al. (27) and others working with nematode virus vectors are notable in the effort spent in tests of validation for the diagnostic markers.

\section{CONCLUSIONS}

The long-term goal of molecular diagnostics is to develop protocols for the accurate and rapid identification of all nematode species. At the Cold Spring Harbor "Taxonomy, DNA, and the Barcode of Life" Conference on September 10-12, 2003 a blueprint was prosposed for implementation of the Barcode of Life Project (54a). Among the list of potential organisms for pilot projects were nematodes, justified, in part, because of current efforts to establish a DNA-based taxonomy. One message emerging from current diagnostic research is that the ITS region has sufficient information to diagnose most nematode species. There are, however, cases where ITS will misdiagnose species, such as the mitotically parthenogenetic species of Meloidogyne and other species of recent hybrid origin. Also, many species 
of Tylenchinae clearly possess several variant ITS sequences within individuals (T. Powers, personal observation). For greater confidence in species delimitation and ultimately successful barcoding, additional unlinked genetic regions are necessary for better diagnostic coverage of the phylum. The mitochondrial gene COI is one good candidate that would complement ITS as a locus unlinked to the nuclear ribosomal gene region. Additionally, COI could help resolve questions of parentage in species of hybrid origin and link to ongoing barcoding efforts in other groups of animals. The $18 \mathrm{~S}$ gene is surprisingly informative at the species level in Nematoda and has the advantage of direct incorporation into the Nematode Tree of Life. As a barcode of slightly coarser taxonomic resolution, $18 \mathrm{~S}$ can readily be incorporated into current studies of nematode biodiversity. Above all, it must be recognized that species determinations have an essential practical application in nematology. Regulatory decisions depend on quick, accurate identification. Increasingly, economic management options require greater resolution in nematode identification. Right now, in 2004, the primary focus of molecular diagnostics in nematology should be building the sequence database through the systematic addition of more species, more isolates and extensive collateral data.

\section{The Annual Review of Phytopathology is online at http://phyto.annualreviews.org}

\section{LITERATURE CITED}

1. Al-Banna L, Williamson V, Gardner SL. 1997. Phylogenetic analysis of nematodes of the genus Pratylenchus using nuclear 26S rDNA. Mol. Phylogenet. Evol. 7:94102

2. Amiri S, Subbotin SA, Moens M. 2002. Identification of the beet cyst nematode Heterodera schachtii by PCR. Eur. J. Plant Pathol. 108:497-506

3. Armstrong M, Blok V, Phillips M. 2000. A multipartite mitochondrial genome in the potato cyst nematode Globodera pallida. Genetics 154:181-92

3a. Besansky NJ, Severson DW, Ferdig MT. 2003. DNA barcoding of parasites and invertebrate disease vectors: what you don't know can hurt you. Trends in Parasitology 19:545-46

4. Bernard EC. 1992. Soil nematode biodiversity. Biol. Fertil. Soils 14:99-103

5. Blaxter M. 1998. Caenorhabditis elegans is a nematode. Science 282:2041-46

6. Blaxter M. 2003. Counting angels with DNA. Nature 421:122-24
7. Blaxter M, De Ley P, Garey JR, Lui LX, Scheldeman P, et al. 1998. A molecular evolutionary framework for the phylum Nematoda. Nature 392:71-75

8. Blok VC, Phillips MS, Fargette M. 1997. Comparison of sequences from the ribosomal DNA intergenic region of Meloidogyne mayaguensis and other major tropical root-knot nematodes. J. Nematol. 29:16-22

9. Blok VC, Wishart J, Fargette $M$, Berthier K, Phillips MS. 2002. Mitochondrial DNA differences distinguishing Meloidogyne mayaguensis from the major species of tropical root-knot nematodes. Nematology 4:773-81

10. Blouin MS. 2002. Molecular prospecting for cryptic species of nematodes: mitochondrial DNA versus internal transcribed spacer. Int. J. Parasitol. 32:52731

11. Boag B, Yeates GW. 1998. Soil nematode biodiversity in terrestrial ecosystems. Biodivers. Conserv. 7:617-30 
12. Brito J, Powers TO, Mullin PG, Inserra RN, Dickson DW. 2004. Morphological and molecular characterization of Meloidogyne mayaguensis isolates from Florida. J. Nematol. 36:In press

13. Brown WM. 1985. The mitochondrial genome of animals. In Molecular Evolutionary Genetics, ed. RH MacIntyre, pp. 95-130. New York: Plenum

14. Bulman SR, Marshall JW. 1997. Differentiation of Australasian potato cyst nematode $(\mathrm{PCN})$ populations using the polymerase chain reaction (PCR). NZ J. Crop Hortic. Sci. 25:123-29

15. Carta LK, Skantar AM, Handoo ZA. 2001. Molecular, morphological and thermal characters of 19 Pratylenchus spp. and relatives using the D3 segment of the nuclear LSU rRNA gene. Nematropica 31:195-209

16. Chen P, Roberts PA, Metcalf AE, Hyman BC. 2003. Nucleotide substitution patterning within the Meloidogyne rDNA D3 region and its evolutionary implications. J. Nematol. 35:404-10

17. Clapp JP, Van Der Stoel CD, Van Der Putten WH. 2000. Rapid identification of cyst (Heterodera spp., Globodera spp.) and root-knot (Meloidogyne spp.) nematodes on the basis of ITS2 sequence variation detected by PCR-single-strand conformational polymorphism (PCR-SSCP) in cultures and field samples. Mol. Ecol. 9:1223-32

18. Dautova M, Overmars H, Bakker J, Smant G, Gommers F. 2002. Nuclear and mitochondrial DNA polymorphisms in three mitotic parthenogenetic Meloidogyne spp. Eur. J. Plant Pathol. 108:209-10

19. De Ley IT, De Ley P, Vierstraete A, Karssen G, Moens M, et al. 2002. Phylogenetic analyses of Meloidogyne small subunit rDNA. J. Nematol. 34(4):319-27

20. De Ley P, Blaxter M. 2002. Systematic position and phylogeny. In The Biology of Nematodes, ed. DL Lee, pp. 1-30. London: Taylor \& Francis

20a. De Ley P, Burt W. 2002. Video capture and editing as a tool for the storage, distribution, and illustration of morphological characters of nematodes. J. Nematol. 34:296-302

20b. Duncan LW, Inserra RN, Thomas WK, Dunn D, Mustika I, et al. 1999. Molecular and morphological analysis of isolates of Pratylenchus coffeae and closely related species. Nematropica 29:61-80

21. Fargette M, Phillips M, Blok V, Waugh R, Trudgill D. 1996. An RFLP study of relationships between species population and resistance-breaking lines of tropical species of Meloidogyne. Fundam. Appl. Nematol. 2:193-200

22. Floyd R, Abebe E, Papert A, Blaxter M. 2002. The $\mathrm{NoOH}$ single-nematode DNA extraction method. http://nema.cap. ed.ac.uk/npg/naoh.html. April

23. Floyd R, Abebe E, Papert A, Blaxter M. 2002. Molecular barcodes for soil nematode identification. Mol. Ecol. 11:839-50

24. Guirao P, Moya A, Cenis JL. 1995. Optimal use of random amplified polymorphic DNA in estimating the genetic relationship of four major Meloidogyne spp. Phytopathology 85:547-51

25. Hebert PDN, Cywinska A, Ball SL, de Waard JR. 2003. Biological identifications through DNA barcodes. Proc. $R$. Soc. London Ser. B 270:313-22

26. Hebert PDN, Cywinska A, Ball SL, de Waard JR. 2003. Barcoding animal life: cytochrome c oxidase subunit 1 divergences among closely related species. Proc. R. Soc. London Ser. B 270:S96-S99

27. Hubschen J, Kling L, Ipach U, Zinkernagel V, Bosselut N, et al. 2004. Validation of the specificity and sensitivity of species-specific primers that provide a reliable molecular diagnostic for Xiphinema diversicaudatum, $X$. index, and $X$. vuittenezi. Eur. J. Plant Pathol. In press

28. Hugall A, Moritz C, Stanton J, Wolstenholme DR. 1994. Low, but strongly structured mitochondrial DNA diversity in root-knot nematodes (Meloidogyne). Genetics 136:903-12 
29. Hugall A, Stanton J, Moritz C. 1997. Evolution of the AT rich mitochondrial DNA of Meloidogyne hapla. Mol. Biol. Evol. 14:40-48

30. Hugall A, Stanton J, Moritz C. 1999. Reticulate evolution and the origins of ribosomal internal transcribed spacer diversity in apomictic Meloidogyne. Mol. Biol. Evol. 16(2):157-64

31. Hyman BC. 1988. Nematode mitochondrial DNA: anomalies and applications. $J$. Nematol. 20:523-31

32. Ibrahim SK, Baldwin JG, Roberts PA, Hyman BC. 1997. Genetic variation in Nacobbus aberrans: an approach toward taxonomic resolution. J. Nematol. 29: 241-49

33. Janzen DH. 2004. Now is the time. Philos. Trans. R. Soc. In press

34. Jatala P. 1993. Nacobbus aberrans, one species or more? Nematropica 23:120

35. Jatala P, Golden M. 1977. Taxonomic status of Nacobbus species attacking potatoes in South America. Nematropica 7:910

36. Jones JT, Phillips MS, Armstrong MR. 1997. Molecular approaches in plant nematology. Fundam. Appl. Nematol. 20:114

37. Lavrov DV, Brown WM. 2001. Trichinella spiralis mtDNA: a nematode mitochondrial genome that encodes a putative ATP8 and normally structured tRNAs and has a gene arrangement relatable to those of coelomate metazoans. Genetics 157:621-37

37a. Luna R, Chitambar JJ. 2003. The California Department of Food and Agriculture. The Nematology Sample Processing Laboratory. http://www.cdfa.ca.gov/phpps/ $\mathrm{ppd} /$ Nematology/NemaLabChanges/Proc Lab/NemaSampleProcLab.htm. November

38. Lund HD, Whipple EL, Hyman CB. 1998. Mitochondrial DNA variable number tandem repeats (VNTRs): utility and problems in molecular ecology. Mol. Ecol. 7:1441-55
39. McKeand JB. 1998. Molecular diagnosis of parasitic nematodes. Parasitology 117:S87-S96

40. Mulholland V, Carde L, O'Donnell KJ, Fleming CC, Powers TO. 1996. Use of the polymerase chain reaction to discriminate potato cyst nematode at the species level. BCPC Symp. Proc. no. 65: Diagn. Crop Prod., pp. 247-52

41. Neher DA. 2001. Nematode communities as ecological indicators of agroecosystem health. In Agroecosystem Sustainability: Developing Practical Strategies, ed. SR Gliessman, pp. 105-20. Boca Raton, FL: CRC Press

42. Okimoto R, Chamberlin HM, Macfarlane JL, Wolstenholme DR. 1991. Repeated sequence sets in mitochondrial DNA molecules of root knot nematodes (Meloidogyne): nucleotide sequences, genome location and potential for host-race identification. Nucleic Acids Res. 19:1619-26

43. Orui Y. 1996. Discrimination of the main Pratylenchus species (Nematoda: Pratylenchidae) in Japan by PCR-RFLP analysis. Appl. Entomol. Zool. 31:505-14

44. Orui Y. 1998. Identification of Japanese species of the genus Meloidogyne (Nematoda: Meloidogynidae) by PCR-RFLP analysis. Appl. Entomol. Zool. 33:43-51

45. Pennisi E. 2003. Modernizing the tree of life. Science 300:1692-97

46. Perlman SJ, Spicer GS, Shoemaker DD, Jaenike JJ. 2003. Associations between mycophagous Drosophila and their Howardula nematode parasites: a worldwide phylogenetic shuffle. Mol. Ecol. 12:237-49

47. Petersen DJ, Vrain TC. 1996. Rapid identification of Meloidogyne chitwoodi, M. hapla and M. fallax using PCR primers to amplify their ribosomal intergenic spacer. Fundam. Appl. Nematol. 19:601-5

48. Powers TO, Harris TS. 1993. A polymerase chain reaction method for the identification of five major Meloidogyne species. J. Nematol. 25:1-6 
49. Reid A, Podrucka K. 2004. Interspecific genetic diversity of 50 Steinernema species as determined by RFLP analysis of the ITS region. Nematology: In press

50. Siddiqi MR. 2000. Parasites of Plants and Insects. Wallingford, UK: CABI Publ. 2nd ed.

51. Stanton J, Hugall A, Moritz C. 1997. Nucleotide polymorphisms and an improved PCR-based mtDNA diagnostic for parthenogenetic root-knot nematodes (Meloidogyne spp.) Fundam. Appl. Nematol. 20:261-68

51a. Stanton JM, McNicol CD, Steele V. 1998. Non-manual lysis of second-stage Meloidogyne juveniles for identification of pure and mixed samples based on the polymerase chain reaction. Aust. Plant Pathol. 27:112-15

52. Stratford R, Shields R. 1994. A transspliced leader RNA sequence in plant parasitic nematodes. Mol. Biochem. Parasitol. 67:147-55

52a. Stein L, Boa Z, Blasiar D, Blumenthal T, Brent M, et al. 2003. The genome sequence of Caenorhabditis briggsae: a platform for comparative genomics. PLOS Biol. 1:166-92

53. Stevens JR, Schofield CJ. 2003. Phylogenetics and sequence analysis-some problems for the unwary. Trends Parasitol. 19:582-88

54. Stoeckle M. 2003. Taxonomy, DNA and the barcode of life. BioScience 53:796-97

54a. Stoeckle M, Janzen D, Hallwachs W, Hanken J, Baker J. 2003. Taxonomy, DNA, and the Barcode of Life. Draft Conference Report. http://phe.rockefeller.edu/ BarcodeConference/index.html

55. Stratford R, Shields R, Goldsbrough AP, Fleming C. 1992. Analysis of repetitive DNA sequences from potato cyst nematodes and their use as diagnostic probes. Phytopathology 82:881-86

56. Subbotin SA, Sturhan D, Rumpenhorst HJ, Moens M. 2003. Molecular and morphological characterisation of the Heterodera avenae species complex
(Tylenchida:Heteroderidae). Nematology 5:515-38

57. Subbotin SA, Vierstraete A, DeLey P, Rowe J, Waeyenberge L, et al. 2001. Phylogenetic relationships within the cyst-forming nematodes (Nematoda, Heteroderidae) based on analysis of sequences from the ITS region of ribosomal DNA. Mol. Phylogenet. Evol. 21:1-16

58. Subbotin SA, Waeyenberge L, Moens M. 2000. Identification of cyst forming nematodes of the genus Heterodera (Nematoda: Heteroderidae) based on the ribosomal DNA-RFLP. Nematology 2:153-64

59. Subbotin SA, Waeyenberge L, Molokanova IA, Moens M. 1999. Idenification of Heterodera avenae group species by morphometrics and rDNA-RFLP. Nematology 1:195-207

60. Tanha Maafi Z, Subbotin SA, Moens M. 2003. Molecular identification of cystforming nematodes (Heteroderidae) from Iran and a phylogeny based on ITS-rDNA sequences. Nematology 5:99-111

61. Uehara T, Mizukubo T, Kushida A, Momota Y. 1998. Identification of Pratylenchus coffeae and $P$. loosi using specific primers for PCR amplification of ribosomal DNA. Nematologica 44:357-68

62. Vahidi H, Curran J, Nelson DW, Webster JM, McClure MA, et al. 1988. Unusual sequences, homologous to 5S RNA, in ribosomal DNA repeats of the nematode Meloidogyne arenaria. J. Mol. Biol. 27:222-27

63. Wang $\mathrm{X}$, Bosselut $\mathrm{N}$, Castagnone $\mathrm{C}$, Voisin R, Abad P, et al. 2003. Multiplex polymerase chain reaction identification of single individuals of the Longidorid nematodes Xiphinema index, $X$ diversicadatum, $X$. vuittenezi, and $X$. italilae using specific primers from ribosomal genes. Phytopathology 93:160-66

64. Waterston RH, Lindblad-Toh K, Birney E, Rogers J, Abril JF, et al. 2002. Initial sequencing and comparative analysis of the mouse genome. Nature 420:520-62

65. Waeyenberge L, Ryss A, Moens M, 
Pinochet J, Vrain TC. 2000. Molecular characteristics of 18 Pratylenchus species using rDNA restriction fragment length polymorphisms. Nematology 2:135-42

66. Whipple LE, Lunt DH, Hyman BC. 1998. Mitochondrial DNA length variation in Meloidogyne incognita isolates of established genetic relationships: utility for nematode population studies. Fundam. Appl. Nematol. 21:265-71

67. Williamson VM, Caswell-Chen EP, Wu FF, Hanson D. 1994. PCR for nematode identification. In Advances in Molecular Plant Nematology, ed. F Lamberti, C De Giorgi, DM Bird, pp. 119-27. New York: Plenum

68. Williamson VM, Caswell-Chen EP, Westerdahl BB, Wu FF, Caryl G. 1997. A PCR assay to identify and distinguish single ju- veniles of Meloidogyne hapla and M. chitwoodi. J. Nematol. 29:9-15

69. Xu J, Liu P, Meng Q, Long H. 2004. Characterisation of Meloidogyne species from China using isozyme phenotypes and amplified mitochondrial DNA restriction fragment length polymorphisms. Eur. J. Plant Pathol. In press

70. Zeng J, Subbotin SA, Waeyenberge L, Moens M. 2000. Molecular characterisation of Chinese Heterodera glycines and $H$. avenae populations based on RFLPs and sequences of rDNA-ITS regions. Russ. J. Nematol. 8:109-13

71. Zijlstra C, Lever AEM, Uenk BJ, Van Silfhout CH. 1995. Differences between ITS regions of isolates of root-knot nematodes Meloidogyne hapla and M. chitwoodi. Phytopathology 85:1231-37 